\title{
Questionando a identidade da literatura: A Legião Estrangeira, de Clarice Lispector
}

Arnaldo Franco Júnior| UNESP/São José do Rio Preto

\begin{abstract}
Resumo: Neste artigo, analisamos como Clarice Lispector vale-se de um material lingüistico usualmente estigmatizado como kitsch para desconstruir a identidade da literatura, ironizando os limites do cânone que institucionaliza a noção de literariedade. Nossa leitura apóia-se na identificação dos procedimentos que, caracterizando a escrita clariciana, constituem-se tanto em estratégias de questionamento e relativização dos valores do sistema literário como, também, em instrumentos de leitura da literatura da escritora.

Palavras-chave: Literatura brasileira do século XX; Conto; Criação literária; Clarice Lispector.
\end{abstract}

\section{Introdução}

$\mathrm{E}_{\mathrm{m}}$ 1964, no mesmo ano em que lançou A paixão segundo G.H., Clarice Lispector publicou A legião estrangeira, que, como ela mesma disse em entrevista ao Museu da Imagem e do Som, "ficou no depósito porque ninguém

1. MELO, 1978. 
prestou atenção nela, foi inteiramente abafado pela Paixão". ' O livro divide-se em duas partes: Contos e Fundo de Gaveta. ${ }^{2}$ Esta divisão demonstra, num primeiro momento, que Clarice estabeleceu uma distinção entre os textos considerados acabados e bem feitos da parte I e os textos dados como inacabados e mal-feitos da parte II. A justificativa que a escritora apresenta na $2^{\underline{a}}$ parte, assim como o título que remete àquilo que "se amontoa, como em todas as casas, no fundo das gavetas", sugere que Clarice Lispector operou com a distinção entre alta e baixa literaturas, separando os textos bem escritos das experiências que falharam ao organizar o livro.

Esta divisão, afinal uma oposição binária, é, no entanto, ultrapassada e questionada, bem como a base conceitual que a sustenta, a saber, os valores canônicos do sistema literário, pela própria construção dos sentidos do livro. Ao organizar o livro em duas partes, Clarice encena uma divisão assentada no bom-senso, no senso de proporção e de medida, no sistema de valores que enforma o senso comum dos que participam do sistema literário para, numa reviravolta, questioná-lo, desestabilizá-lo, avaliando-o como "imposição muito limitadora" como faz em:

Mentir, pensar

O pior de mentir é que cria falsa verdade. (Não, não é tão óbvio como parece, não é truísmo; sei que estou dizendo uma coisa e que apenas não sei dizê-la do modo certo, aliás o que me irrita é que tudo tem de ser "do modo certo", imposição muito limitadora). O que é mesmo que eu estava tentando pensar? Talvez isso: se a mentira fosse apenas a negação da verdade, então este seria um dos modos (negativos) de dizer a verdade. Mas a mentira pior é a mentira "criadora". Não há dúvida: pensar me irrita, pois antes de começar a tentar pensar eu sabia muito bem o que eu sabia.

Este pequeno texto sintetiza boa parte das questões que atravessam A legião estrangeira. Nas crônicas e demais textos que, do Fundo de Gaveta,

2. Nos anos 70, A legião estrangeira foi desmembrado em dois livros, e Fundo de Gaveta foi publicado com o título de Para não esquecer (1978). Tal fato, mantido nas edições posteriores do livro, mutilou, como esperamos demonstrar, o projeto literário original da escritora, afetando a recepção crítica de sua obra.

3. LISPECTOR, 1964, p.127.

4. LISPECTOR, 1964, p.143. 
questionam os valores do sistema que os marginaliza, é constante a discussão sobre o que é e o que não é literatura, o que é fazer ficção, o que é escrever, quais são os limites que definem um gênero literário, enfim, um conjunto de reflexões sobre a identidade do texto literário.

\section{Um elefante no circo}

Da primeira parte de A legião estrangeira, destacaremos o conto "A solução". Neste conto, Clarice explora a estrutura do fait divers: ${ }^{5}$ as personagens pertencem à classe média baixa e estão enoveladas em fatos que, narrados, ganham um quê de sensacionalista e de folhetinesco.

O conto narra a história de duas datilógrafas. Almira, gorda, voraz, ávida de comida e carinho nutre por Alice, que é magra, elegante, discreta e seca de coração, uma amizade que confina com o amor puro e desinteressado, mas intenso. A relação é estática: Almira devota-se a Alice e esta deixa-se adorar. Isso, até que, um dia, notando a tristeza de Alice, Almira insiste em levá-la para almoçar, torna-se inconveniente e recebe uma resposta agressiva da outra. Inconformada, enfia um garfo no pescoço de Alice e acaba presa, ganhando, na cadeia, companheiras e alegria.

A apropriação da estrutura da notícia neste conto não é literal nem estática, mas instrumentalizada para que, a partir dela, teça-se um sutil comentário crítico sobre o mundo-cão que faz do fato narrado algo sensacional e que faz de Almira a encarnação da inocência punida, alguém que só receberá reconhecimento e afeto na cadeia. Note-se que, após configurar o contraste entre Almira e Alice, sublinhando a amizade de mão única da primeira, o narrador registra o olhar coletivo sobre a amizade das duas:

5. Consultar BARTHES, 1978, p.57-67.

6. Segundo Jean-Marie Thomasseau (1984), a virgem humilhada encarna, no romance libertino do século XVIII, o tema da inocência punida. É, neste sentido, um elemento estrutural que integrará o imaginário romântico presente no romance-folhetim e no melodrama, gêneros romanescos posteriores e parentes estruturais do fait divers. Naturalmente, terá valores e funções diferentes num e noutro tipo de romance. 
Por que Alice tolerava Almira, ninguém entendia. Ambas eram datilógrafas e colegas, o que não explicava. Ambas lanchavam juntas, o que não explicava. Saíam do escritório à mesma hora e esperavam condução na mesma fila. Almira sempre pajeando Alice. Esta, distante e sonhadora, deixando-se adorar. Alice era pequena e delicada. Almira tinha o rosto muito largo, amarelado e brilhante: com ela o batom não durava nos lábios, ela era das que comem o batom sem querer.

O conto, no entanto, menos do que narrar uma história de amor homossexual, estrutura tal possibilidade de interpretação como armadilha para o leitor que, ao acatá-la, ver-se-á incluído no bloco daqueles que, no final, passam a fofocar e a levantar hipóteses preconceituosas para explicar a ação violenta de Almira sem compreender que seu devotamento e seu amor eram puros, dessexualizados.

Algumas pessoas observadoras disseram que naquela amizade bem que havia dente-de-coelho. Outras, amigas da família, contaram que a avó de Almira, dona Altamiranda, fôra mulher muito esquisita. Ninguém se lembrou de que os elefantes, de acordo com os estudiosos do assunto, são criaturas extremamente sensíveis, mesmo nas grossas patas.

A incorporação do fait divers em "A solução" não é um fim em si mesma, mas ponto de partida para, como é comum em muitos dos textos de Clarice, afirmar o não-lugar do amor inocente e desinteressado em nossa sociedade. Almira encarna, no texto, tanto o bobo da aldeia como a vièrge souillé. Desta forma, os atributos da vilania deslocam-se para o mundo que a cerca. A estrutura social, portanto, passa a ser vista como circo de horrores, mundo-cão, sistema que transforma o amor e a inocência em algo bizarro, já que faz de Almira, tão sensível quanto gorda, um elefante no circo quando, feliz, ganha companheiras e reconhecimento na cadeia.

7. LISPECTOR, 1964, p.80.

8. LISPECTOR, 1964, p.82.

9. O bobo da aldeia e a virgem humilhada pertencem à morfologia das personagens do romance folhetim (ECO, 1991) e do melodrama (HUGO et alii, 1985), que, não por acaso, têm sua origem vinculada, também, ao fait divers. 
Clarice espalha pelo conto detalhes que garantem o acionamento, pela recepção, do gatilho sensacionalista: Almira é comilona, muito gorda e muito delicada - o que sugere um paradoxo ou nota picante, mas flagra e desarma um preconceito muito comum: Almira é ingênua a ponto de não desconfiar que sua devotada amizade era passível de ser vista como homossexualidade pela maledicência dos que a cercam e, também, passível de funcionalização por Alice, que a usa; Alice é magra, elegante, interesseira e oportunista; Almira enfia um garfo no pescoço de Alice num restaurante (o que se constitui no cúmulo, ${ }^{10}$ elemento fundamental do fait divers, dada a conexão cômico-irônica que articula a ação e os atributos da personagem que a executa com o lugar em que se manifesta) e termina simultânea e paradoxalmente punida e premiada na cadeia: presa e feliz.

O final do conto, no entanto, rompe com a lógica conservadora do fait divers pois não faz de Almira uma encarnação do mal social, não a demoniza para sustentar, intocada, a estrutura social de que ela faz parte. ${ }^{11}$ Ao contrário: Clarice faz da punição um prêmio para a personagem, mas sem deixar de criticá-la:

Na prisão Almira comportou-se com docilidade e alegria, talvez melancólica, mas alegria mesmo. Fazia graça para as companheiras. Finalmente tinha companheiras. Ficou encarregada da roupa suja, e dava-se muito bem com as guardiães, que vez por outra lhe arranjavam uma barra de chocolate. Exatamente como para um elefante no circo. ${ }^{12}$

10. O cúmulo é um dos elementos estruturais característicos do fait divers (BARTHES, 1978). É ele que garante um sabor especial, articulando o efeito sensacional com o choque, a surpresa, a curiosidade, pois enlaça, numa mesma rede, aspectos contrários que se aproximam, normalmente, do absurdo.

11. Um dos traços característicos do fait divers é a conservação da estrutura social. Isso acontece porque, ao singularizar um fato, qualquer que ele seja, o fait divers tende a desvinculá-lo da estrutura social da qual faz parte. Isso é evidente nas notícias de página policial de jornal: criminoso e vítima são como que desvinculados da ordem social da qual fazem parte para encarnarem uma dimensão de essência, respectivamente, do Mal e do Bem. Desta forma, demoniza-se o criminoso, santifica-se a vítima, e a estrutura social permanece intocada na medida mesma em que o crime é definido, nesta estrutura discursiva, como fato extraordinário.

12. LISPECTOR, 1964, p.82. 
O narrador critica a alegria de Almira, avaliando-a como melancólica. Critica a alienação da personagem, conformada com o lugar que lhe é destinado, e, também, a marginalização dos valores que, no texto e na vida, Almira encarna: amor desinteressado, amizade, calor humano nas relações interpessoais, vontade de alegria. A última frase do trecho acima destacado volta-se, também, para a própria sociedade que faz de Almira um bicho de circo, encarcerando-a. Com ironia, Clarice faz da punição um prêmio para Almira. Deste modo, criticará personagem e sociedade, descerrando, na interação de ambas, a evidência de que vivemos num mundo-cão.

O conto tem semelhança, estrutural inclusive, com outras situações dramáticas presentes na obra de Lispector, caracterizadas pela apreensão, via ótica e via imaginário coletivo, de um fato que envolve a ação, externa e interna, da personagem principal e seu resultado. O povo, aí, as pessoas que, reunidas, debruçam-se, entre mórbidas e divertidas, sobre o fato e a personagem, cumpre função próxima à do coro na tragédia grega: comenta a ação do herói, suas razões e suas conseqüências. Entretanto, numa inversão, tal função é alienadora, já que desfigura e reduz a grandeza da personagem à mesquinharia e à vulgaridade daqueles que a comentam.

A ação desta personagem coletiva, que remete à ordem dos valores e às estruturas sociais, é o atestado do fracasso do herói clariciano, signo de sua solidão e de sua incomunicabilidade, signo da adulteração, repressiva, de seus propósitos, esperanças, de sua busca e de seus valores. Nos textos de Clarice, a ação desta personagem coletiva é marcada pela presença de linguagem ordinária afeita aos clichês, aos estereótipos, aos preconceitos, à maledicência, ao kitsch. É esta voz coletiva que se manifesta em alguns textos de Fundo de Gaveta, ainda que travestida, em alguns deles, de voz individual.

\section{Do fundo da gaveta}

Intitulada Fundo de Gaveta, a segunda parte de A legião estrangeira reúne textos de natureza diversa: pensamentos, frases que registram instantes de iluminação poética, crônicas, notas sobre artes plásticas e espetáculos, reflexões sobre o ato de escrever e a literatura, um pequeno exercício de dramaturgia, contos etc. Há, no conjunto, dois traços que se destacam: a) um constante exercício de reflexão sobre escrever, criar, fazer arte e literatura; b) um constante exercício de, por meio da escrita, experimentar ser o outro que 
ocupa a posição de personagem protagonista. Em muitos desses textos, há uma dupla perspectivização que faz com que a alteridade seja enfocada de dentro e de fora de sua experiência singular.

No primeiro caso, destacam-se os textos em que Clarice se põe a discutir os limites dos gêneros literários e, além disso, aqueles em que a relação entre o escrever e a temática social é posta em causa. Note-se:

\section{Romance}

Ficaria mais atraente se eu o tornasse mais atraente. Usando, por exemplo, algumas das coisas que emolduram uma vida ou uma coisa ou romance ou um personagem. É perfeitamente lícito tornar atraente, só que há o perigo de um quadro se tornar quadro porque a moldura o fez quadro. Para ler, é claro, prefiro o atraente, me cansa menos, me arrasta mais, me delimita e me contorna. Para escrever, porém, tenho que prescindir. A experiência vale a pena, mesmo que seja apenas para quem escreveu. ${ }^{13}$

Observe-se a consciência quanto a saber tornar "mais atraente" o texto, valendo-se de procedimentos e recursos que agradariam uma recepção automatizada pelo hábito e por uma produção literária que referendasse os paradigmas usuais de crítica, gosto e recepção do texto literário. Note-se, também, a inflexibilidade quanto a fazer concessões ao sistema literário, resistência que a escritora manteve até o fim da vida, mesmo quando obrigada a escrever por encomenda.

Em "Escrever, humildade, técnica", Clarice identifica o seu "problema" quanto a escrever:

Essa incapacidade de atingir, de entender, é que faz com que eu, por instinto de... de quê? Procure um modo de falar que me leve mais depressa ao entendimento. Esse modo, esse "estilo" (!), já foi chamado de várias coisas, mas não do que realmente e apenas é: uma procura humilde. Nunca tive um só problema de expressão, meu problema é muito mais grave: é o de concepção. (...) Humildade como técnica é o seguinte: só se aproximando com humildade da coisa é que ela não escapa totalmente. ${ }^{14}$

13. LISPECTOR, 1964, p.139.

14. LISPECTOR, 1964, p.144 - grifos nossos. 
A substância dessa humildade se constitui numa espécie de indiferença soberana que parece melhor esclarecida no final do texto "Aventura", também voltado para o ato e o compromisso de escrever, traduzindo-se como "aproximação mais isenta e real em relação a viver e, de cambulhada, a escrever". 15

É esta isenção que permite a Clarice Lispector articular em quiasmo ${ }^{16}$ as situações dramáticas que cria, valendo-se do paradoxo para extrair, nos textos, as muitas possibilidades de sentido que caracterizam a afirmação simultânea de contrários que se cruzam numa mesma experiência.

Não só as personagens claricianas experimentam o paradoxo e a afirmação simultânea de contrários que se afirmam e se anulam, se harmonizam e se digladiam mortalmente. Também, o texto clariciano aspira instalar-se no puro devir, ${ }^{17}$ participando e escapando simultaneamente do centro e da periferia do sistema literário e, numa constante, voltando-se contra as limitações de ambos. É com este mesmo propósito que também o kitsch, ${ }^{18}$ tal como definido pela tradição modernista, será mobilizado pela escritora. Ele não deve ser apenas lido em suas manifestações mais evidentes, em geral, delimitadas e definidas a partir da tradição e dos valores que animam e sustentam o sistema literário e cultural de nossa sociedade, mas deve ser lido, também, como resultado de uma avaliação crítica que nasce de um revés do olhar, que se firma como questionamento ao que quer que se afirme aprioristicamente como belo, bom, ideal.

15. LISPECTOR, 1964, p.146.

16. É Nádia Battella Gotlib (1988) quem identifica o quiasmo - disposição em X de termos que se repetem em ordem contrária numa frase ou verso como pertinente à arquitetura dos textos de Clarice Lispector.

17. O puro devir manifesta-se como afirmação simultânea de dois sentidos contrários "que não se detêm nunca (...) sempre furtando-se ao presente, fazendo coincidir o futuro e o passado, o mais e o menos, o demasiado e o insuficiente na simultaneidade de uma matéria indócil. (...) O paradoxo desse puro devir (...) é a identidade infinita: identidade infinita dos dois sentidos ao mesmo tempo". (DELEUZE, 1974).

18. Kitsch é uma palavra alemã incorporada, no século XX, ao discurso da crítica de arte identificada com o programa modernista e à reflexão sobre a questão da arte na Modernidade. O termo serviu para a identificação de obras que apresentavam - segundo uma concepção de arte como atividade desinteressada (Kant) e de obra como o resultado equilibrado de uma articulação orgânica de elementos contrastivos (Aristóteles) - um desequilíbrio entre os elementos e a função estéticos e aqueles elementos e funções ligados a outros sistemas de valor (comerciais, políticos, morais, religiosos, pedagógicos etc.). Ver: MOLES, 1971 e ECO, 1970. 
Em "Literatura e justiça", Clarice dialoga diretamente com as patrulhas ideológicas que lhe cobravam textos engajados, que exigiam que ela fosse uma intelectual participante nos termos do que este rótulo significou no Brasil dos anos 60. Assumindo a sua incapacidade de responder, escrevendo, nos termos do que lhe exigiam, Clarice estabelece uma distinção entre escrever e fazer algo de concreto para resolver os problemas sociais, afirmando-se envergonhada de "não contribuir com ações" . ${ }^{19}$ E, recusando antecipadamente qualquer absolvição dessa vergonha, rejeita o referendum ao sistema de valores de onde ele procede ao arrematar o texto com uma adversativa final: "Mas de escrever o que escrevo não me envergonho: sinto que, se eu me envergonhasse, estaria pecando por orgulho". ${ }^{20}$

No que se refere aos textos que registram o exercício de ser o outro, destacamos os retratos de mulheres velhas, empregadas domésticas, escritoras fracassadas. A velha de "Instantâneo de uma senhora", por exemplo, aproximase da D. Aninha do conto "Feliz aniversário". Tal como D. Aninha, experimenta, na condição de traste, coisa velha, estar à margem do sistema no qual, sugere o texto, já ocupara o centro. Tanto é assim que, ao surpreender os moradores da pensão em que mora, retornando de uma inesperada visita à casa do filho, abraça-se à vacuidade dos estereótipos que nada mais são do que a ideologia que cerca a família como instituição:

Disse que passara o domingo na casa do filho, onde pernoitara. Estava de vestido preto de cetim já apagado; em vez de ir para o quarto mudar de roupa e ser uma pessoa da pensão, sentou-se na sala de visitas e disse que a família era a base da sociedade. Referiu-se de passagem a um banho de imersão que tomara na confortável banheira da nora. ${ }^{21}$

A velha, que é inicialmente descrita como uma espécie de magnífica ruína - "volumosa, cheirava a quando a galinha vem meio crua para a mesa. Tinha cinco dentes e a boca seca" 22 -, acaba vomitando, nauseada com a lembrança da visita à casa do filho: "Na hora em que elogiou o passadio magnífico da casa do

19. LISPECTOR, 1964, p.149.

20. LISPECTOR, 1964, p.150.

21. LISPECTOR, 1964, p.135.

22. LISPECTOR, 1964, p.134. 
filho seus olhos se fecharam de náusea. Recolheu-se, vomitou, recusou ajuda quando lhe bateram à porta do quarto".

O contraste entre a velha e a magnificência da comida cotidiana na casa do filho é metafórico: sinaliza as duas margens inconciliáveis da experiência que, no entanto, e ironicamente, encontram-se unidas pelos laços de família. Alijada do "centro do mundo", a velha reage com a náusea. Mas é aqui, precisamente, que o conflito se presentifica, tal como em "Feliz aniversário", como espetáculo corporal. A náusea é um índice de mal-estar profundo que sacode os corpos da velha: o da pensionista, o da mãe de família e um outro, avesso à ordem da sociedade administrada, que se imiscui entre ambos e vive sob a ameaça permanente da funcionalização. Há um conflito entre estes corpos, que alegorizam a alienação a que a personagem se encontra sujeita no plano das representações sociais, e o corpo fluido, outro, que a anima a passear, banhar-se, vomitar. A representação a que os corpos socialmente reconhecidos e validados se prestam evidencia-se no contraste entre o "vestido preto de cetim já apagado e o vestido de estampazinha de ramagem" usado sem soutien pela velha no final de sua aventura. Só a náusea - metáfora orgânica de recusa e negação da alienação, do mau gosto do bom gosto - dignifica a velha porque é o que lhe permite chegar à conclusão de que "Fôra feliz inutilmente". ${ }^{25} \mathrm{~A}$ náusea é o que se contrapõe visceralmente à alienação, instalando uma descontinuidade na experiência cotidiana que obriga aquele que a experimenta a pensar, a reconhecer criticamente a sua experiência, a dissociar-se, ainda que momentaneamente, dos lugares-comuns da ideologia com a qual se conforma.

"Mal-estar de um anjo", escrito na $1^{\text {a }}$ pessoa, relata as torturas por que passa a narradora quando, num dia de chuva torrencial, cede ao apelo de uma outra mulher e divide o táxi que ocupava. A outra, muito agradecida e continuamente chamando a narradora de "anjo", logo se torna abusiva - o que obriga a narradora a reagir com dureza, após fazer o jogo, com ironia que a outra nem percebe, da conversação amigável.

Este explicita o poderoso mito de descondicionamento que se afirma

23. LISPECTOR, 1964, p.135.

24. LISPECTOR, 1964, p.135.

25. LISPECTOR, 1964, p.135. 
na obra de Clarice Lispector, mito que se instala não como utopia romântica, mas como conquista num mais além do cotidiano. Não há, na obra de Clarice, ilusões quanto à necessidade de reiteradamente construí-lo. A luta é permanente e se trava no feijão com arroz das relações cotidianas, locus por excelência da reatualização coercitiva da ideologia que preside a sociedade administrada. A narradora é explícita quando afirma:

A alegria satisfeitona daquela senhora começava a me deixar sombria: ela fizera uso exorbitante de mim. Fizera de minha natureza indecisa uma profissão definida, transformara minha espontaneidade em dever, acorrentava-me a mim, que era anjo, o que a essa altura eu já não podia mais negar, mas anjo livre. Quem sabe, porém, eu só fora mandada ao mundo para aquele instante de utilidade. Era isso, pois, o que eu valia. No táxi, eu não era um anjo decaído: era um anjo que caía em si. Caí em mim e fechei a cara. (...) Ela, a minha protegida, continuava a falar bem de mim, ou melhor, de minha função. Emburrei. ${ }^{26}$

A tomada de consciência resulta em interrupção da representação, da interação social calcada na reificação, em sabotagem da linguagem comum. Isso vale, no conto, para que a narradora safe-se de ser vítima da gratidão prática da outra, salve-se de ser alienada a ponto de identificar-se com a função elogiada por esta. É de se notar que a organização da narrativa, articulada a partir do conflito entre a narradora e a caronista, também faz uso da autora-implícita identificada com a vítima. Tal dado é fundamental para compreendermos o valor e a importância da encenação, de ser o outro realizado como exercício, nem sempre agradável, na literatura de Clarice: ainda que não goste, a narradora experimenta ser "um anjo" para a outra, interrompendo o jogo no momento exato em que ele ameaça aliená-la de seus reais propósitos e interesses. Adere, pois, para melhor resistir. Dá-se o mesmo com o trabalho de Clarice. Seu malestar em relação à literatura, à crítica, à imprensa, ao mercado editorial marcase pelo cuidado de não se deixar funcionalizar, de não se deixar reduzir a rótulos. Este mito de descondicionamento da escrita e da escritora, que se afirma de modo sutil em $A$ legião estrangeira será, posteriormente, radicalizado

26. LISPECTOR, 1964, p.156. 
em outros livros em que a mistura de gêneros, a heteronímia ${ }^{27}$ e a apropriação de elementos considerados kitsch serão as armas utilizadas para desestabilizar as armadilhas da alienação por público, crítica, sistema literário e mercado editorial: $A$ via-crucis do corpo e A bora da estrela.

Destacamos, ainda, em Fundo de Gaveta, o texto "A arte de não ser voraz". Vejamo-lo:

A arte de não ser voraz

- Moi, madame, j'aime manger juste avant la faim. Ça fait plus distingué. ${ }^{28}$

A ironia que preside este minúsculo texto é sutil. Entre o título em português, que remete aos manuais de etiqueta, e a frase em francês, que é uma espécie de instantâneo daquele que a enuncia em meio a uma conversação, estabelece-se tanto um laço de continuidade como um laço de descontinuidade. É a partir deste segundo - operado pela autora implícita que recorta a frase do contexto, utiliza-a como sinédoque para apresentar e representar aquele que, orgulhoso de si, a enuncia ao mesmo tempo em que se distancia da perspectiva por ele adotada -, que se instala a ironia que reverte o bom-tom, o bom-senso e o bom-gosto em kitsch, manifestação ridícula de alienação individual e social, sujeição abjeta à mortificação inerente a determinados comportamentos e ritos sociais. Exemplo de paródia a sério, ${ }^{29}$ a repetição da fala que fotografa seu enunciador não serve para ratificar os valores nem o ponto-de-vista ali expressos. Neste sentido, a repetição, aí, é uma pantomima. Insere-se, pois, um contraste entre o assunto da conversação - a fome - e aquilo que o enunciador revela de si

27. Apoiando-se em Barthes, Benedito Nunes (1982) refere-se, ao analisar A hora da estrela, ao "modo esquizóide de escrever (...) à custa da cisão vertiginosa do sujeito, do desdobramento da consciência reflexiva, mas que funda a ficção e, juntamente com ela, o fictício da identidade do narrador (...), em confronto com a identidade fictícia de seu personagem".

28. LISPECTOR, 1964, p.169.

29. A paródia a sério (HUTCHEON, 1989) é um procedimento que, característico da arte contemporânea, subverte o sentido da paródia tradicional e instala, no contexto de crise da Modernidade e do Modernismo, uma ironia ambivalente em relação ao alvo de sua apropriação crítica. A pop-art, segundo Hutcheon, apresenta uma série de obras que evidenciam o valor e a importância do conceito, já que se apropria, entre outros materiais, do kitsch para questionar os limites entre alta e baixa cultura. 
ao pronunciar-se sobre ele por meio de uma fala falada, ${ }^{30}$ um texto reconhecível como representativo de uma determinada forma discursiva institucionalmente consolidada: o manual de etiqueta. O dialogismo operado pela literatura de Clarice baseia-se preferencialmente na contraposição de blocos ou fragmentos de blocos discursivos, de gêneros literários, de modelos de escrita em vez de basear-se na construção de vozes individualizadas e particularizadas sob a forma de personagens. O recurso ao francês indicia a artificialidade e a futilidade do defensor das boas maneiras, e, na reversão de sentido operada pela ironia, a sua vulgaridade transparece exatamente na finesse: excesso de modos e maneiras, artificialidade pedante da "boa educação" e, sobretudo, cabotinismo nem um pouco comedido daquele que se dirige à sua interlocutora.

$O$ procedimento de base de que Clarice se vale para construir este texto é semelhante àquele empregado por Duchamp na invenção de seus readymades: recorta-se do cotidiano um determinado objeto - no caso, uma frase dita em meio a uma conversação -, desloca-se tal objeto de seu contexto, inserindo-o em outro já na condição de sinédoque. Do contraste entre o objeto recortado e o contexto de destino no qual ele se insere nasce uma tensão irônica que comenta um e outro pólos de constituição da obra.

O urinol de Duchamp, intitulado Fonte, comentava ironicamente a exposição de arte para a qual fora destinado e, também, a própria organização e os valores da entidade responsável pela exposição. O enunciado recortado por Clarice, real ou inventado, ocupa a mesma posição do objeto vulgar e produzido em série que, deslocado de seu contexto, cria um curto-circuito bem-humorado, mas de longo alcance crítico, em relação àquilo que comenta: o mau gosto do bom-gosto, a afetação mal-disfarçada de signo de distinção social, de refinamento e cultura. Nos readymades de Duchamp, é flagrante a tensão estabelecida entre a própria noção tradicional de obra de arte e o que se lhe contrapõe, paradoxalmente, afirmando e negando as noções que lhe são correlatas: originalidade, unicidade, resultado de trabalho, pesquisa e esforço de criação (singularização ${ }^{31}$ ), elaboração

30. A fala falada (MERLEAU-PONTY, 1971) é um sintoma de profunda alienação do indivíduo que, sem desenvolver a capacidade de filtrar individual e criticamente o que herda das instituições sociais e da ideologia, atua como mero reprodutor destas em sua vida e em suas relações e interações sociais, reduzindo-se à condição de depositário de clichês e de estereotipias.

31. O conceito de singularização é definido por Chklovski (1976) como o resultado do emprego, pelo artista, de um conjunto de procedimentos de construção que, juntos, fazem de cada obra de arte algo único. 
árdua de estilo individual que dialoga com os cânones de produção estética de sua época etc.

Em "A arte de não ser voraz", o título irônico e bem-humorado é suficientemente ambíguo para simultaneamente afirmar e negar, constatar e questionar o lugar-comum, reverenciar e zombar do que se apresenta, para aquela que o formula, como evidência da afirmação pessoal de uma "alteridade" que de outra não tem nada. É da interação título-frase recortada que emerge a perspectiva crítica que faz da segunda algo em que o kitsch se inscreve para, numa reversão, voltar-se para o contexto, chamemos assim, com que, em princípio, rivaliza, comentando-o.

O confronto título-frase evidencia duas diferentes vozes e perspectivas: a da narradora-autora, aquela que escolhe e recorta o fragmento de realidade e lhe dá um título, criando um texto, e a da personagem que enuncia a sua frase em $1^{\underline{a}}$ pessoa, construindo uma imagem de si mesma neste mesmo ato.

Como o título remete aos manuais de etiqueta, condensações normativas que visam regular ética e esteticamente a vida em sociedade (as boas maneiras, o bom-tom, a boa educação, as regras de conduta e de convivência civilizadas), há, na interação título-frase recortada tanto adequação como inadequação, tanto concordância de sentido e de propósitos (redundância) como discordância entre tais elementos (disjunção irônica). No $1^{\circ}$ caso, título e frase redundam, afirmando, por meio de uma sinédoque, o requinte de uma vida pautada pelas regras de etiqueta. No $2^{\circ}$ caso, no entanto, título e frase e seus respectivos pólos de enunciação entram em conflito, e a afirmação de bom-gosto, o apego à "justa medida" do ser e do viver são virados pelo avesso pela risada irônica da narradora-autora que, na declaração de seu interlocutor colhe não uma pessoa, mas uma não-pessoa, uma encarnação ambulante do livro de etiqueta.

O suposto bom-gosto da frase, realçado ironicamente pelo registro em língua francesa, converte-se em seu oposto: expressão de mau-gosto, de afetação e de auto-alienação. Quem enuncia a frase revela-se menos humano do que aquela que o observa com uma visada irônica, sabendo que este verniz de distinção não passa de uma precária construção diante da fome, da vivência mesma da fome pelo ser humano.

No confronto entre estas duas vozes, ${ }^{32}$ que são a expressão institucional de valores ideológicos, há, ainda, que se destacar as diferentes línguas:

32. Ver BAKHTIN, 1981. 
português e francês. Há várias possibilidades de leitura abertas pelo indiciamento que elas, como material lingüístico empregado neste texto, sugerem. Há uma conformação sinedóquica, também, em ambas, com o português remetendo a um nós, brasileiros, e o francês remetendo a um eles, franceses, ou, ainda, com o português remetendo ao Brasil ( $3^{\circ}$ mundo, subdesenvolvimento, miséria, "barbárie") e o francês remetendo à França (1ำ mundo, desenvolvimento, riqueza, "civilização" ${ }^{33}$. Mas há, também, a possibilidade de que o francês, ali, não seja senão a expressão de alguém que, tão brasileiro como seu interlocutor, tenha tido a oportunidade de aprender o francês - e, aqui, pode-se ler: escola, educação, classe social, pode-se ler o indiciamento de classe social que pressupõe certa estabilidade e conforto, certa afluência de meios e de bens, que permitem que as regras de etiqueta sejam observadas e cumpridas com o objetivo de afirmar uma distinção não apenas individual, mas de classe social.

O que é, então, afirmação de elegância e superioridade reverte-se no seu contrário, admitido não como verdade de fundo do texto, mas tãosomente como uma $2^{\underline{a}}$ possibilidade tão válida como a 1 $1^{\mathrm{a}}$. Deste modo, o vértice crítico, ocupado pelo leitor capaz de ver, este verbo tão importante na obra de Clarice, uma e outra possibilidades, dispõe de uma horrível liberdade de escolha entre uma e outra possibilidades ou, tal como sugere o texto em sua composição, postar-se diante de ambas.

\section{Considerações Finais}

Para as nossas considerações finais, retomaremos a nota explicativa que justifica o Fundo de Gaveta de A legião estrangeira. Nessa nota, insinua-se o propósito de perturbar as distinções entre alta e baixa literaturas, bem como o sistema de onde elas procedem. Lispector vale-se de Otto Lara Resende e de Manuel Bandeira para justificar, diante da possibilidade da morte, a necessidade de ser encontrada pela indesejada das gentes com "a casa limpa, a mesa posta, com cada coisa em seu lugar". "No entanto, ironizará o sistema de valores e a ordem classificatória dos quais o desejo de ordem e limpeza procede:

33. A língua, a cultura e os costumes franceses foram, sobretudo da segunda metade do século XIX à primeira metade do século XX, signos de distinção social na sociedade brasileira.

34. LISPECTOR, 1964, p.127. 
Por que publicar o que não presta? Porque o que presta também não presta. Além do mais, o que obviamente não presta sempre me interessou muito. Gosto de um modo carinhoso do inacabado, do malfeito, daquilo que desajeitadamente tenta um pequeno vôo e cai sem graça no chão. ${ }^{35}$

O que há de tão atraente no que "não presta"? É que o que "não presta" seduz. E o faz porque, ao falhar, instaura uma pane no sistema de valores que permite identificar algo como "falho". O que "não presta" pode ser divertido e, de um modo perverso, virar do avesso o "modo certo" de ser, de viver, de escrever - "imposição muito limitadora", afinal. O que "não presta", portanto, não é o "crime" que se insinua na falha, no fracasso, mas a indiferença soberana que ignora completamente tais categorias e se afirma como cegueira luminosa do sujeito que atravessa as possibilidades de individualização e seus dramas, defendendo o seu direito à constituição de uma identidade fluida, avessa a cristalizações e sua fatal conseqüência: a reificação.

Tal como a escultora burguesa de $A$ paixão segundo $G H$ vive a paixão como deseroização, despojamento radical das personae em favor do descentramento da subjetividade e do encontro com a alteridade - afinal, a barata também é o que "não presta", o neutro vivo de Deus - Clarice Lispector parece interessada no despojamento radical da persona de escritora para poder engajar-se n'A legião estrangeira. Isso se torna visível quando observamos a estrutura arquitetônica que rege a construção deste livro de contos.

A arquitetura de $A$ legião estrangeira faz uso da especularidade: os contos da $1^{\underline{a}}$ parte são contrapostos aos textos da $2^{\underline{a}}$, e, por fim, o livro termina sugerindo que o eixo de oposições binárias inicialmente afirmado é ultrapassado em favor do escrever e do escrito, e não da hierarquia de valores do sistema literário. Clarice Lispector sabota, pois, Clarice Lispector. A que escreve sabota a escritora, interessada em dar continuidade à experimentação de novos meios e materiais, em não se deixar encarcerar pelas armadilhas do sucesso e do sistema literário. Este cuidado com a disposição dos textos que enformam um livro já era visível, por exemplo, em Laços de família, em que "O jantar" ocupa posição central, reunindo, como num microcosmo, a estrutura especular marcada pela "travessia dos contrários" "36 bem como a temática que a escritora vai

35. LISPECTOR, 1964, p.127.

36. Consultar SÁ, 1993. 
obsessivamente explorar nos demais contos em que as relações familiares são a tônica.

Se em A paixão segundo GH a personagem principal, já anônima, conquista, num processo de deseroização, a anonímia que a liberta, em $A$ legião estrangeira - cujo projeto original inclui os textos de Fundo de Gavetaé Clarice Lispector que está às voltas com a libertação do cárcere de escritora, problemática que aprofundará nos anos 70 até chegar à radicalidade de Um sopro de vida.

Abstract: This paper analyzes how Clarice Lispector uses a kind of linguistic material usually stigmatized as kitsch to deconstruct the identity of literature, ironizing the limits of the canon that institutionalizes the notion of literariness. This reading is based on the identification of the procedures that characterize Lispector's writing and, at the same time, are strategies of criticism and relativization of literary system values, as well as instruments to read the author's literature.

Key words: Twentieth Century Brazilian literature; Short story; Literary creation; Clarice Lispector.

\section{Referências Bibliográficas}

BAKhtin, M. Problemas da poética de Dostoiévski. Rio de Janeiro: Forense Universitária, 1981.

BARTHES, R. A estrutura da notícia. In: Crítica e verdade. São Paulo: Perspectiva, 1978. p. 57-67.

CHKLÓSVKI, V. Arte como procedimento. In: EIKHEMBAUM, B. Teoria da literatura - Formalistas russos. Porto Alegre: Globo, 1976. p.39-60.

DeLEuZE, G. Lógica do sentido. São Paulo: Perspectiva, 1974.

ECO, U. O super-homem de massa. São Paulo: Perspectiva, 1991.

ECO, U. A estrutura do mau gosto. In: Apocalípticos e integrados. São Paulo: Perspectiva, 1970. p. 69-128.

GOTLIB, N. B. Uma aprendizagem dos sentidos. In: Três vezes Clarice. Rio de Janeiro: CIEC/ Escola de Comunicação da UFRJ, 1989, v.7, p.12-24.

HUGO, A.; MALITOURNE, A.; ADER, J-J. Tratatto del melodrama. Parma: Pratiche Editrice, 1985. 
HUTCHEON, L. Uma teoria da paródia. Lisboa: Edições 70, 1989.

LISPECTOR, C. A legião estrangeira. Rio de Janeiro: Editora do Autor, 1964.

LISPECTOR, C. A descoberta do mundo. Rio de Janeiro: Nova Fronteira, 1984. p.643644.

LISPECTOR, C. A via-crucis do corpo. 2. ed. Rio de Janeiro: Nova Fronteira, 1984.

LISPECTOR, C. A hora da estrela. 6. ed. Rio de Janeiro: Francisco Alves, 1981.

MELO, M. A. (sel. e org.) Dezembro sem Clarice - Depoimento a Affonso Romano de Sant'Anna e Marina Colasanti para o arquivo do MIS -RJ. Escrita, São Paulo: Vertente, v.27, p.20-24, 1978.

MERLEAU-PONTY, M. Fenomenologia da percepção. Rio de Janeiro: Freitas Bastos, 1971.

MOLES, A. O Kitsch - Arte da felicidade. 2. ed. São Paulo: Perspectiva, 1975.

NUNES, B. Clarice Lispector ou o naufrágio da introspecção. Colóquio-Letras, Lisboa: Fundação Calouste Goulbenkian, v.70, p.13-22, 1982.

SÁ, O. A travessia do oposto. São Paulo: Annablume, 1993.

THOMASSEAU, J.M. Le mélodrame. Paris: Presses Universitaires de France, 1984. 